\title{
Comparison of various growth functions for predicting long-term stand development associated with different initial spacing in 64-year-old Japanese cedar (Cryptomeria japonica (L.f.) D. Don) plantations
}

\author{
Che-Yu Shih', Tian-Ming Yen', Ya-Nan Wang ${ }^{2}$
}

Shih C.-Y., Yen T.-M., Wang Y.-N., 2021. Comparison of various growth functions for predicting long-term stand development associated with different initial spacing in 64-year-old Japanese cedar (Cryptomeria japonica (L.f.) D. Don) plantations. Ann. For. Res. 64(1): 87-97.

Abstract Establishing a plantation with varied distances between trees is one way to control stand density in an initial growth stage. Understanding how stand growth patterns are influenced by initial spacing can help maximize growth and yield. The purpose of this study was to examine the long-term effects of different patterns of initial tree spacing on stand development. A spacing trial with five initial distances, namely, treatments I: $1 \times 1 \mathrm{~m}, \mathrm{II}: 2 \times 2$ m, III: $3 \times 3 \mathrm{~m}$, IV: $4 \times 4 \mathrm{~m}$, and V: $5 \times 5 \mathrm{~m}$, was established in 1950 in Japanese cedar (Cryptomeria japonica (L.f.) D. Don) plantations in central Taiwan, managed by the Experimental Forest of National Taiwan University. Each treatment had three repetitions, and all plots were surveyed from 1955 to 2014, with eight records for each time series. We simultaneously employed six growth functions to predict stand basal area growth for each plot and assessed their predictability using the root mean square error (RMSE) as a criterion. Consequently, a total of twelve plots covering all treatments except treatment I, each with six RMSEs resulting from various models, were obtained. The repeated measures analysis of variance approach was adopted to compare predictability among models. The Richards growth function performed the best compared to all the other models. As a result, this model was used to analyse stand development following different initial spacing. We found that the predicted curves could effectively exhibit the growth patterns resulting from different initial spacing. Moreover, the parameters help explain some characteristics of stand development, such as growth potential and maximum growth rate achieved $\left(t_{\max }\right)$. As a result, a clear trend emerged, showing that, with decreasing initial spacing, the growth potential increased and the $t_{\max }$ decreased. These results provided valuable information for managing the stand density of this conifer.

Keywords: spacing trial, stand density, Richards growth function, repeated measures analysis of variance.

Addresses: ${ }^{1}$ Department of Forestry, National Chung Hsing University, Taichung City, Taiwan| ${ }^{2}$ School of Forestry and Resource Conservation, National Taiwan University, Taipei, Taiwan.

$\square$ Corresponding Author: Tian-Ming Yen (tmyen9999@gmail.com).

Manuscript received August 21, 2020; revised May 24; accepted May 25, 2021. 


\section{Introduction}

Over $60 \%$ of the area in Taiwan was covered by forest of three main types: natural, plantation, and bamboo (Taiwan Forestry Bureau (TFB) 2020, Yen et al. 2020). Plantation forests occupy over 440,000 ha and play a critical role in the current forest management due to their high productivity and strong carbon fixation capability, as well as their high commercial benefits and multiple uses (Chiu et al. 2010, Cheng et al. 2013, Yen 2015, Yen et al. 2020). Most plantations were established after natural forests were logged (Yen 2015). On the other hand, to avoid a large area of pure stands, different tree species might be chosen to establish plantations even under the same environmental conditions. As a result, current plantation forest systems often consist of a mosaic of small monocultures (about 5-10 ha) currently spread across the landscape (Yen 2015, TFB 2020, Yen et al. 2020).

Japanese cedar (Cryptomeria japonica (L.f.) D. Don) is one of the most important non-native conifers in Taiwan. It was first introduced from Japan more than 100 years ago (Young 1975, Cheng et al. 2013). Because of the suitable environment in Taiwan, this conifer was widely planted across mountain regions, mostly at elevations between 1000 to $2000 \mathrm{~m}$ (Liu et al. 1994, TFB 2020). Moreover, most Japanese cedar plantations were pure stands in Taiwan (Yen et al. 2020). Usually, the planted density ranged from 2,000 to 3,300 stems ha ${ }^{-1}$. As a result, it comprises approximately $10 \%$ of Taiwanese plantations and is especially prevalent in northern and central Taiwan (Cheng et al. 2013, Yen et al. 2020). Japanese cedar plantation possesses economic and environmental benefits due to its excellent wood properties and high productivity. The wood of this conifer with high economic values could provide for multiple uses, such as siding, furniture and panelling (Lin \& Lin 2013). On the other hand, the plantation of this conifer was reported to have high potential of carbon storage in Taiwan and Japan (Fukuda et al. 2003, Yen et al. 2020).

Numerous studies have addressed its growth and yield fields. Important studies include the establishment of site index models (Wang et al. 2012), the comparison of stand growth under different densities (Shih et al. 1997) and the assessment of the ability of biomass accumulation and carbon storage (Cheng et al. 2013, Yen et al. 2020). The above results provide quantified growth and yield information to inform the management of Japanese cedar plantations. Although many studies have focused on the growth and yield fields for the Japanese cedar, rare studies on long-term development after different initial spacing for this conifer in Taiwan, especially for stands over 60 years of age (Lam \& Guan 2020). Monitoring long-term development of stands that were established with various initial spacing can help determine the best strategy for stand density management (Baldwin et al. 2000, Masaki et al. 2006, Nishizono et al. 2008, Gizachew et al. 2012, Kitagawa et al. 2018).

The present study addressed the long-term effects of initial spacing on stand development in 64-year-old Japanese cedar plantations. We employed six growth functions, namely, the Schumacher, Mitscherlich, Logistic, Gompertz, Richards, and ModifiedWeibull growth functions, to quantify stand development following different initial spacing. The objectives of this study were to (1) quantify stand growth based on the growth functions, (2) compare the predictive capacity of different growth functions, and (3) examine stand development following different initial spacing via growth functions for Japanese cedar plantations.

\section{Materials and Methods}

\section{Study area}

The study area was located in the Nantou 
County of central Taiwan. A long-term initial spacing trial of Japanese cedar plantations was carried out, which belongs to the Experimental Forest of National Taiwan University (EFNTU). The plantations were located in the 3rd component of Sitou District of EFNTU (120 39' 56" E, 234' $40 " \mathrm{~N})$, at an elevation of approximately $1,200 \mathrm{~m}$. The site had an average monthly temperature range of $11.6-23.1^{\circ} \mathrm{C}$, an average annual temperature of $18.4^{\circ} \mathrm{C}$, an average annual rainfall of $2,397 \mathrm{~mm}$ year $^{-1}$ and soil texture was fine sandy loam (The Experimental Forest, College of BioResources and Agriculture, National Taiwan University 2018).

This trial adopted different initial spacing to establish Japanese cedar plantations since 1950. A total of five treatments of different initial spacing were installed, namely, the treatment I: $1 \times 1 \mathrm{~m}\left(10,000\right.$ stems $\left.\mathrm{ha}^{-1}\right)$, II: $2 \times 2 \mathrm{~m}\left(2,500\right.$ stems ha $\left.\mathrm{ha}^{-1}\right)$, III: $3 \times 3 \mathrm{~m}$ $\left(1,111\right.$ stems ha $\left.{ }^{-1}\right)$, IV: $4 \times 4 \mathrm{~m}$ (625 stems $\left.\mathrm{ha}^{-1}\right)$, and V: $5 \times 5 \mathrm{~m}$ (400 stems ha $\left.{ }^{-1}\right)$. A randomized block design was employed in this trial, which consisted of three blocks of five treatments each. Each block was 0.1 ha in size $(40 \times 25 \mathrm{~m})$, resulting in a total experimental area of 1.5 ha. In addition, to avoid interaction effects among treatments, a five $m$ wide buffer was installed to isolate each plot (Shih et al. 1997).

According to historical records, the three plots of treatment I were thinned in 1965, when the stand was 15 years old. Because the trees in this treatment were overcrowded at that time, managers decided to remove $40 \%$ of number of trees from treatment I by thinning from below (Shih et al. 1997). Since this treatment was disturbed by thinning, it was not included in further analysis.

\section{Study methods}

The objective of this study was to analyse stand development following the different initial spacing used in the permanent trial plots. Five treatments with fifteen plots were established in 1950 and first surveyed in 1955. These permanent plots were surveyed again in 1960, 1965, 1979, 1985, 1996, 2004, and 2014. The diameter at breast height (DBH) of all the trees was measured within the plots for each time. We calculated the basal area (BA) of each individual tree $\left(\mathrm{BA}=\pi \times \mathrm{DBH}^{2} / 4\right)$ and used BA per hectare $\left(\mathrm{m}^{2} \mathrm{ha}^{-1}\right)$ as a stand characteristic for each plot and each survey. Likewise, we obtained the BA of all the plots within the different time series. However, the dataset contained some missing values and unreasonable values for individual trees. For examples, in some cases, records of some trees were lacking from certain surveys but included in later surveys. In other cases, the data for certain trees was unreasonable and assumed to reflect error. We dealt with these types of values as mistakes and used the same approach to correct them. This approach adopted the periodical mean values to replace the incorrect ones. For instance, if a tree had records in 1960 and 1970 but not in 1965, we employed the mean DBH of 1960 and 1970 as the value for this tree in 1965. Likewise, the same approach was used to replace the unreasonable values. To understand the distribution of mistakes among the treatments, the ratios of the incorrect values to all the data (including the incorrect values) of each treatment were calculated to be $3.67 \%, 6.81 \%, 2.48 \%$, $5.23 \%$ and $7.38 \%$ for treatments I, II, III, IV and V, respectively.

Stand development was displayed at the plot and treatment levels, where the former used the single plot with times as the dataset, and the later adopted the same treatments (combination of three plots) as the dataset. Six growth functions were used to quantify stand development. These functions are shown in Table 1. 
Table 1 The six types of growth functions used in this study.

\begin{tabular}{ll}
\hline Name & Model type $^{\text {a }}$ \\
\hline Schumacher & $Y=\exp [A-B(1 / t)]$ \\
Mitscherlich & $Y=A\left[1-B \exp ^{-C t}\right]$ \\
Logistic & $Y=A /\left[1+B \exp ^{-C t}\right]$ \\
Gompertz & $Y=A \exp \left[-B \exp ^{-C t}\right]$ \\
Richards & $Y=A[1-\exp (-B t)]^{1 /(1-C)}$ \\
Modified- & $Y=A\left[1-\exp \left(-B t^{C}\right)\right]$ \\
Weibull & \\
\hline
\end{tabular}

${ }^{a} Y$ is basal area per ha; $t$ is stand age; and $A, B$ and $C$ are parameters of the models

Single plots were simultaneously subjected to these six growth functions to predict their growth performance. After prediction, the root mean square error (RMSE) was used to assess model performance in fitness. The formula for the RMSE is as follows (Draper \& Smith 1981):

$$
\text { RMSE }=\sqrt{\frac{\sum_{i=1}^{n}\left(Y_{i}-\bar{Y}_{i}\right)^{2}}{n-p}}(1
$$

where $Y_{i}$ and $\hat{Y}_{i}$ are the $i$ observation and the predicted value by the model; $n$ is the total number of observations, where $n=8$ in this study (each plot with eight surveys); and $p$ is the number of parameters for the models ( $p=2$ for the Schumacher model; $p=3$ for the other models).

Since the six growth functions were employed to predict the same dataset, each plot obtained six RMSEs resulting from the different models. Thus, the data type is suitable for examination by the repeated measures analysis of variance (RM-ANOVA). We used RM-ANOVA to examine the RMSE among the growth functions and then used the Least Significant Difference (LSD) test to calculate their difference when the RM-ANOVA demonstrated significant differences at $\alpha=0.05$. Because the purpose of the above test was to assess the predictability among the growth functions at the plot level, we did not further examine the difference in the RMSE among the treatments in this step.

At the treatment level, a best model (the smallest RMSE) from the above analysis was chosen to predict stand development resulting from initial spacing. The three plots within the same treatments were combined as a dataset. We utilized the growth pattern predicted by the best model to compare the growth processes among the treatments with different initial spacing.

\section{Results}

\section{Stand development following different treatments}

We integrated the data from the different treatments with survey periods and focused on the surviving trees, mean $\mathrm{DBH}$ and BA of stands to compare the effects of different initial spacing. Since each treatment contained three plots, the means of these plots were utilized to show different treatments. The developments of these stand characteristics with various initial spacing are shown in Figure 1. In general, surviving trees decreased and the other two stand characteristics increased with increasing stand age, regardless of treatment.

Table 2 The stand characteristics of all treatments with in Japanese cedar plantations in 2014 (64-years-old).

\begin{tabular}{lllll}
\hline Treatments & $\begin{array}{l}\text { Surviving trees } \\
\left.(\text { trees ha })^{-1}\right)\end{array}$ & $\begin{array}{l}\text { Survival } \\
\text { ratio }(\%)\end{array}$ & $\begin{array}{l}\text { Mean } \\
\mathrm{DBH} \\
(\mathrm{cm})\end{array}$ & $\begin{array}{l}\text { Basal area } \\
\left(\mathrm{m}^{2} \mathrm{ha}^{-1}\right)\end{array}$ \\
\hline II & $740.0 \pm 130.0^{\mathrm{a}}$ & $29.6 \pm 5.2$ & $37.0 \pm 0.9$ & $82.9 \pm 11.5$ \\
III & $516.7 \pm 72.3$ & $46.5 \pm 6.5$ & $40.1 \pm 2.0$ & $68.6 \pm 3.6$ \\
IV & $450.0 \pm 26.5$ & $72.0 \pm 4.2$ & $44.1 \pm 1.1$ & $72.3 \pm 0.6$ \\
V & $293.3 \pm 49.3$ & $73.3 \pm 12.3$ & $45.2 \pm 0.4$ & $48.8 \pm 10.0$ \\
\hline
\end{tabular}

${ }^{\mathrm{a}}$ Mean \pm standard deviation 


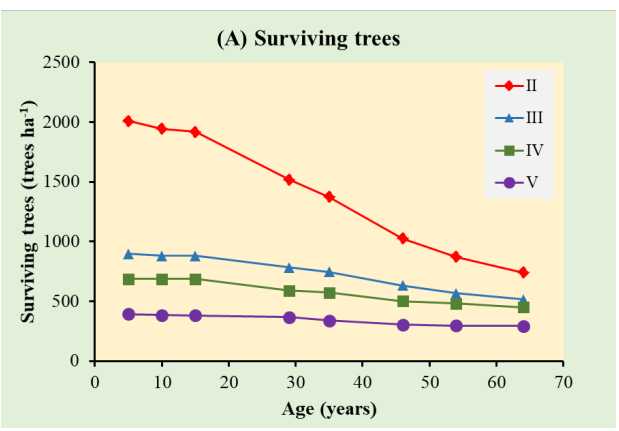

(B) Mean diametr at breast height (DBH)

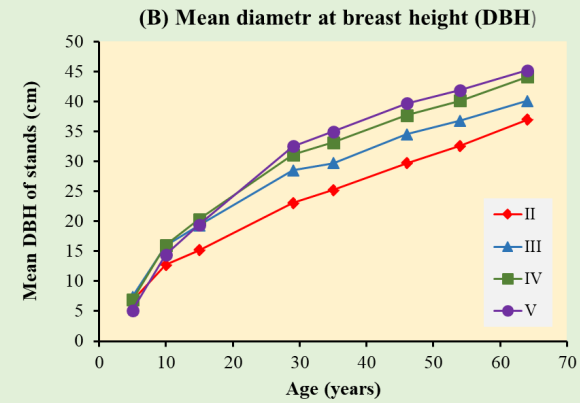

(C) Basal area (BA)

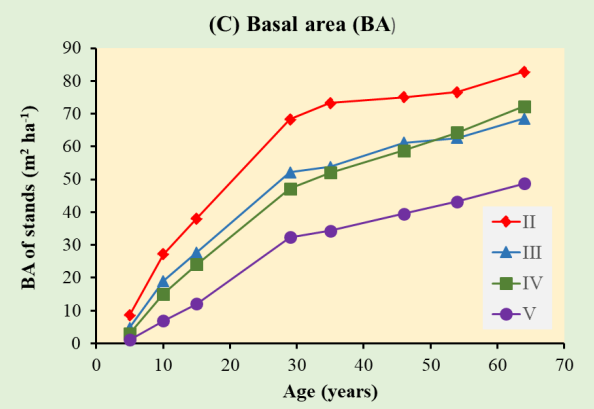

Figure 1 Tree survival, mean $\mathrm{DBH}$ and $\mathrm{BA}$ of stands with different initial spacing treatments in Japanese cedar plantations.

Moreover, the stand characteristics of all treatments at the final survey (64-year-old plantations) are illustrated in Table 2. A clear trend showed that the survival of trees, survival ratio and $\mathrm{BA}$ decreased, whereas the mean DBH increased with wider initial spacing.

\section{Comparisons of the RMSE among the models}

The parameters and RMSE of the relevant growth functions were obtained for each sample plot after prediction. To understand the parameters and RMSE within each treatment, their distributions are illustrated in Table 3.

Notably, the purpose of this study was not to assess which model was most suitable for specific treatments but to evaluate all the plots across treatments. Therefore, assessing the predictability of the models at the plot level was used for single plots as one unit and was not based on treatments. Since the six RMSEs resulting from the relevant models were obtained for each plot, their performance was compared based on the twelve sample plots.

We examined the predictability of the models using the RM-ANOVA method. Typically, the data structure should follow the assumption of sphericity before examining the procedure of RM-ANOVA; otherwise, the data structure should be corrected. However, the data of the RMSE were found to violate the assumption of sphericity after examining using the sphericity test. Therefore, we adopted the Greenhouse-Geisser approach to correct the data. As a result, the corrected F-value $=14.824(p<0.001)$, indicating that the RMSE showed differences among the models. Their differences were examined by the LSD test and are shown in Table 4.

The smallest RMSE value $\left(2.451 \pm 0.741 \mathrm{~m}^{2} \mathrm{ha}^{-1}\right)$ was found in the Richards model, which was superior to the Modified-Weibull, Gompertz and Logistic models, whereas there was no significant difference with the Mitscherlich and Schumacher models when using the LSD test. The results showed that the Richards model had performed well in modelling stand developments of Japanese cedar in response to initial spacing. 
Table 3 The parameters and root mean squared error (RMSE) of the models within each treatment.

\begin{tabular}{|c|c|c|c|c|c|}
\hline \multirow{2}{*}{ Models } & \multirow{2}{*}{$\begin{array}{l}\text { Parameters and } \\
\text { RMSE }\left(\mathrm{m}^{2} \mathrm{ha}^{-1}\right)\end{array}$} & \multicolumn{4}{|c|}{ Tratament } \\
\hline & & II & III & IV & $\mathrm{V}$ \\
\hline \multirow[t]{3}{*}{ Schumacher } & $A$ & $4.62 \pm 0.17^{\mathrm{a}}$ & $4.46 \pm 0.03$ & $4.55 \pm 0.04$ & $4.24 \pm 0.26$ \\
\hline & $B$ & $13.46 \pm 3.22$ & $15.92 \pm 2.08$ & $20.31 \pm 2.87$ & $24.58 \pm 6.06$ \\
\hline & RMSE & $3.42 \pm 1.10$ & $2.74 \pm 0.90$ & $2.58 \pm 0.60$ & $1.76 \pm 0.49$ \\
\hline \multirow[t]{4}{*}{ Mitscherlich } & $A$ & $84.49 \pm 15.00$ & $72.81 \pm 6.20$ & $86.09 \pm 9.99$ & $64.66 \pm 29.54$ \\
\hline & $B$ & $1.24 \pm 0.09$ & $1.18 \pm 0.11$ & $1.13 \pm 0.07$ & $1.18 \pm 0.09$ \\
\hline & $C$ & $0.062 \pm 0.016$ & $0.046 \pm 0.014$ & $0.032 \pm 0.013$ & $0.031 \pm 0.015$ \\
\hline & RMSE & $3.16 \pm 1.61$ & $2.52 \pm 1.06$ & $2.01 \pm 0.77$ & $2.19 \pm 0.43$ \\
\hline \multirow[t]{4}{*}{ Logistic } & $A$ & $78.37 \pm 11.75$ & $65.29 \pm 0.455$ & $68.81 \pm 1.98$ & $45.79 \pm 10.11$ \\
\hline & $B$ & $12.04 \pm 3.96$ & $11.80 \pm 5.89$ & $11.36 \pm 1.00$ & $19.68 \pm 0.16$ \\
\hline & C & $0.161 \pm 0.034$ & $0.131 \pm 0.045$ & $0.108 \pm 0.022$ & $0.129 \pm 0.023$ \\
\hline & RMSE & $3.83 \pm 0.59$ & $3.93 \pm 0.62$ & $4.45 \pm 0.34$ & $2.93 \pm 0.98$ \\
\hline \multirow[t]{4}{*}{ Gompertz } & $A$ & $79.83 \pm 12.37$ & $67.02 \pm 4.80$ & $72.33 \pm 3.49$ & $48.37 \pm 12.18$ \\
\hline & $B$ & $3.59 \pm 0.64$ & $3.45 \pm 0.95$ & $3.34 \pm 0.30$ & $4.43 \pm 0.20$ \\
\hline & $C$ & $0.110 \pm 0.022$ & $0.088 \pm 0.027$ & $0.070 \pm 0.018$ & $0.081 \pm 0.019$ \\
\hline & RMSE & $3.01 \pm 1.10$ & $3.15 \pm 0.18$ & $3.32 \pm 0.45$ & $2.17 \pm 0.76$ \\
\hline \multirow[t]{4}{*}{ Richards } & $A$ & $81.25 \pm 13.19$ & $69.93 \pm 6.63$ & $79.36 \pm 7.72$ & $51.33 \pm 15.37$ \\
\hline & $B$ & $0.088 \pm 0.022$ & $0.066 \pm 0.030$ & $0.046 \pm 0.020$ & $0.062 \pm 0.020$ \\
\hline & $C$ & $0.525 \pm 0.112$ & $0.436 \pm 0.209$ & $0.395 \pm 0.118$ & $0.606 \pm 0.056$ \\
\hline & RMSE & $2.72 \pm 1.50$ & $2.55 \pm 0.45$ & $2.45 \pm 0.62$ & $1.91 \pm 0.62$ \\
\hline \multirow[t]{4}{*}{ Modified-Weibull } & $A$ & $79.82 \pm 12.71$ & $68.71 \pm 6.82$ & $77.10 \pm 6.92$ & $49.06 \pm 13.66$ \\
\hline & $B$ & $0.012 \pm 0.008$ & $0.012 \pm 0.008$ & $0.009 \pm 0.001$ & $0.003 \pm 0.001$ \\
\hline & $C$ & $1.55 \pm 0.21$ & $1.45 \pm 0.33$ & $1.37 \pm 0.13$ & $1.72 \pm 0.07$ \\
\hline & RMSE & $2.77 \pm 1.42$ & $2.62 \pm 0.37$ & $2.68 \pm 0.66$ & $2.16 \pm 0.64$ \\
\hline
\end{tabular}

${ }^{\mathrm{a}}$ Mean \pm standard deviation

Table 4 The root mean squared error (RMSE) examined by the Least Significant Difference (LSD) test for the six growth models.

\begin{tabular}{lll}
\hline Model & Sample & RMSE $^{1,2)}\left(\mathrm{m}^{2} \mathrm{ha}^{-1}\right)$ \\
\hline Richards & 12 & $2.405 \pm 0.827^{\mathrm{a}}$ \\
Mitscherlich & 12 & $2.471 \pm 1.011^{\mathrm{abc}}$ \\
Modified-Weibull & 12 & $2.558 \pm 0.777^{\mathrm{b}}$ \\
Schumacher & 12 & $2.625 \pm 0.927^{\mathrm{abc}}$ \\
Gompertz & 12 & $2.912 \pm 0.762^{\mathrm{c}}$ \\
Logistic & 12 & $3.787 \pm 0.811^{\mathrm{d}}$ \\
\hline
\end{tabular}

${ }^{1)}$ Mean \pm standard deviation

${ }^{2)}$ The means of the models marked with the same letter indicate no significant difference at $p=0.05$ by the LSD test.

\section{An illustration of the Richards model to show stand development}

For the above comparison at the plot level, the Richards model stands out among all the models (Table 4). We employed this model as an illustration to display stand BA developments following various initial spacing. Since the purpose of this comparison was to display stand development at the treatment level, we combined three repeated plots (each with eight observations) within a treatment as a unit. This combination indicated that a total of twentyfour observations resulting from three repeated plots were obtained in each treatment. 
After prediction, the parameters, as well as $R^{2}$ and RMSE in each treatment, are shown in Table 5. (from 1.91 to $2.72 \mathrm{~m}^{2} \mathrm{ha}^{-1}$ ) compared to the same treatments with the Richards model. However, the previous prediction (Table 3) was at the plot

Table 5 The parameters of Richards model, $R^{2}$ and root mean squared error (RMSE) for the basal area growth under different treatments.

\begin{tabular}{lccccc}
\hline \multirow{2}{*}{ Treatments } & \multicolumn{3}{c}{ Parameters } & \multirow{2}{*}{$R^{2}$} & RMSE $\left(\mathrm{m}^{2} \mathrm{ha}^{-1}\right)$ \\
\cline { 2 - 4 } & $A$ & $B$ & $C$ & & \\
\hline II & 80.9362 & 0.0823 & 0.5037 & 0.922 & 8.000 \\
III & 68.4605 & 0.0631 & 0.4430 & 0.976 & 3.677 \\
IV & 76.9920 & 0.0444 & 0.3898 & 0.981 & 3.475 \\
V & 49.9707 & 0.0564 & 0.5830 & 0.932 & 4.845 \\
\hline
\end{tabular}

${ }^{\mathrm{a}}$ Mean \pm standard deviation

Parameter $A$ decreased from treatment II to $\mathrm{V}$. However, parameters $B$ and $C$ did not have a clear trend, increasing or decreasing, following the increase of the initial spacing. Moreover, a high $R^{2}$ (over 0.9) was found across the treatments, indicating that model worked well forall treatments. The values of RMSE ranged from 3.48 to $8.00 \mathrm{~m}^{2}$ ha $^{-1}$ (Table 5), which was higher than that in Table 3

(A) Stand development of treatment

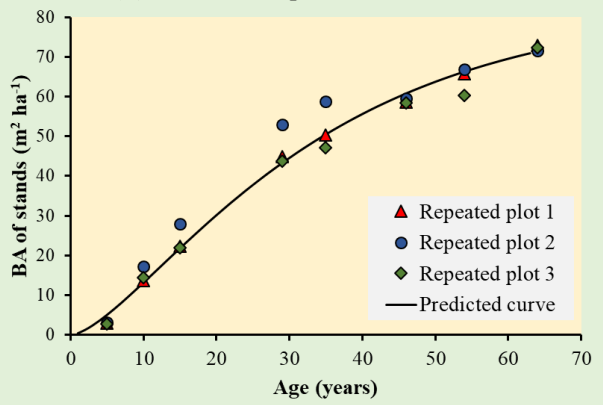

(C) Stand development of repeated plot 2

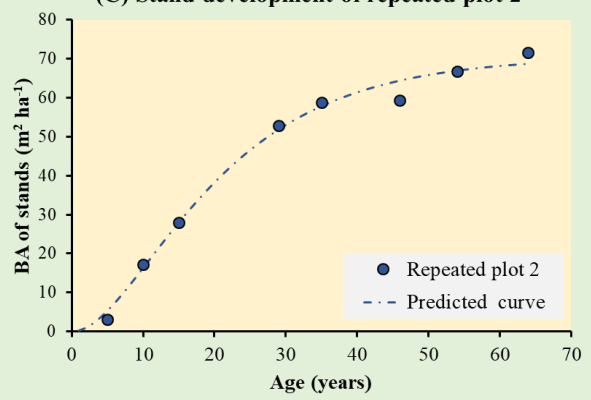

level (each only eight observations), whereas this illustration (Table 5) was at the treatment level (each with twentyfour observations). More observations might possibly lead to larger variance in model prediction; therefore, a larger RMSE was expected.

To show the predictive effects at the plot and treatment levels, treatment IV was used as an example. We utilized the Richards model to predict treatment IV (contains three plots) and three individual plots. The relationships between the observations and the predicted curves are shown in Figure 2.

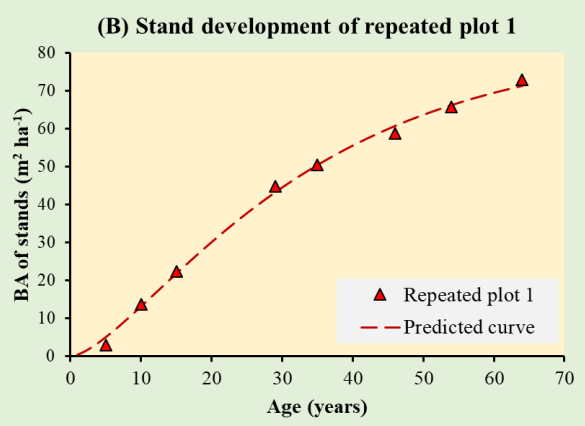

(D) Stand development of repeated plot 3

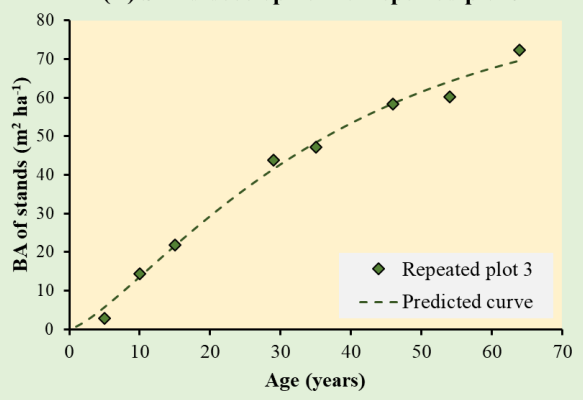

Figure 2 An illustration of treatment IV to exhibit the relationships between the observations and the curve predicted by the Richards model at the treatment and plot levels. 
The observations and predicted curves were displayed at the plot and treatment levels (Figure 2 A-D). At the plot level, each surveyed year only had an observation, and the smaller RMSE in each plot was expected $\left(1.7320,2.8389\right.$ and $2.7701 \mathrm{~m}^{2} \mathrm{ha}^{-1}$ for the repeated plots 1,2 , and 3 , respectively). Since treatment IV pooled three plots as datasets, a larger RMSE (3.4748 $\mathrm{m}^{2} \mathrm{ha}^{-1}$ ) was obtained than that at the plot level. Usually, combinations of data increasing variance is reasonable in model prediction. Nevertheless, we found that the curve of the Richards function passes through the observations smoothly, regardless of the plot or treatment level, indicating that this model could effectively predict BA development at the plot and treatment levels.

Likewise, we employed the same approach to display growth curves for the other treatments, and all treatments are shown in Figure 3. Furthermore, the curve of current increment of BA (Figure 3B) was derived from the total increment of the same parameter (Figure 3A) for each treatment. We found that a regular growth pattern was exhibited in stand development for different initial space based on the Richards function. These curve systems help explain the effects of initial spacing on stand developments.

\section{Discussions}

In this study, we found that surviving trees obviously decreased with time in the stands with lower initial spacing (e.g., treatment II). However, the mean $\mathrm{DBH}$ and $\mathrm{BA}$ were affected differently by increases in initial spacing. For instance, the stands with wider initial spacing had a larger mean $\mathrm{DBH}$ and a smaller BA during the same period of stand development. Because stands with larger initial space provided more space for individual tree development, lower mortality and larger DBH growth were expected (Clutter et al. 1983). In contrast, a smaller BA was found in stands with wider initial spacing because fewer trees were planted in these plots in spite of each tree having a larger DBH. Similar results were found in stands after thinning, where larger DBH growth occurred at individual tree level, because more space was created by thinning. Meanwhile, thinning trees resulted in lower stocking at the stand level (Yen 2015). Although the present study focused on BA development of stands following various initial spacing, the information about the surviving trees and their mean DBH helps understand BA development because of the strong correlation among these three stand characteristics.
(A) Total increment of basal area (BA)

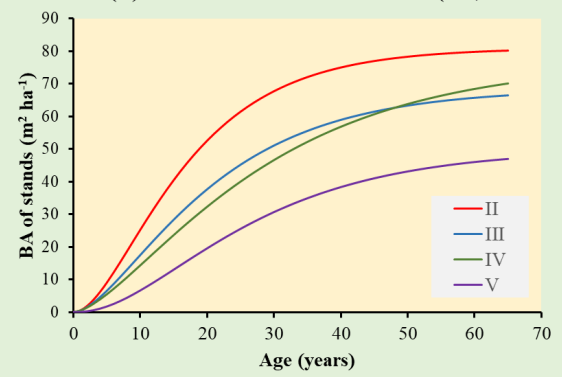

(B) Current increment of BA

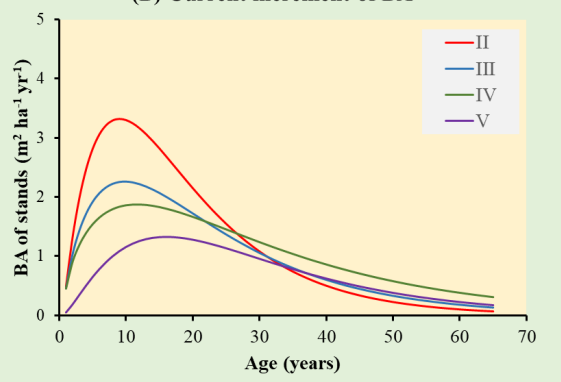

Figure 3 The pattern of total increment and current increment curves predicted by the Richards model with various initial spacing. 
Numerous studies have applied the Richards model to predict the development of various forests at individual plant and stand levels worldwide and obtained satisfactory results due to flexibility.For instance, Ito and Osumi (1984) used this model to predict the basal area growth of pure stands of Japanese cedar and Japanese cypress (Chamaecyparis obtusa (Sieb. et Zucc.) Endl.), and the results showed that the model can effectively fit the data for both tree species. Yen (2016) employed this model to predict culm height growth for Moso bamboo (Phyllostachys pubescens Mazel) plantations and the parameters of Richards growth function could satisfactorily explain culm height growth under different diameter classes. Gizachew et al. (2012) utilized this model to predict BA and volume growth for Norway spruce (Picea abies L.) stands in response to initial spacing and site. As a result, this model can effectively quantify how stand development varies with these two factors. Our study also confirms the superiority of the Richards model in predicting stand BA development in response to initial spacing.

According to the classified curve type, we found that most of the models used in the present study had a sigmoid-type structure. In addition to the Mitscherlich model, the other five models possessed this property. Usually, an "inflection point" reflects the maximum growth rate in the sigmoid-type model. Noticeably, we found that the Mitscherlich model also fits the data well with a smaller RMSE value $\left(2.471 \pm 1.011 \mathrm{~m}^{2} \mathrm{ha}^{-1}\right)$ and was not significantly different from the Richards, Modified-Weibull, Schumacher and Gompertz models, according to the LSD test. However, this model was significantly superior to the Logistic model (Table 4), suggesting that the model with a sigmoid-type structure might not be a key factor in its predictability. Although the Mitscherlich model displays a decreasing pattern in the current increment (growth rate), it still can fit the data well. We found a possible reason that might be relative to the data structure. Due to there being a total of only eight collection times for our survey data spaced by intervals of 5-11 years, their growth patterns might not be easy to display a clear sigmoid-type pattern. This is displayed in Figure 1(C). Therefore, the Mitscherlich model can also have advantages in fitting data.

Among the predictability of the five models with a sigmoid type, the Logistic model had the largest RMSE, indicating that this model was inferior to the others in predictability, because its growth rate is limited to a symmetrical type (Richards 1959). We inferred that this limitation was a possible reason to lead to its higher RMSE compared to the other models.

An affinity between the Richards models and the Mitscherlich, Logistic and Gompertz models was proposed by Richards (1959). This study also confirmed that the Richards model could widely cover the Mitscherlich, Logistic and Gompertz models at a certain status when its parameters $C=0,2$ and approaching 1 are equal to the Mitscherlich, Logistic and Gompertz models, respectively. From the above growth model system, we found that the Richards and Mitscherlich models are more suitable for quantifying stand development of Japanese cedar in response to initial spacing.

On the other hand, an important advantage of the Richards model is its parameters with geometrical meanings that can effectively explain the curve properties, where the parameter $A$ indicates growth potential and the parameters $B$ and $C$ affect certain curve shapes of the Richards function (Richards 1959, Pienarr \& Turnbull 1973, Yen 2016). In addition, the maximum growth rate $\left(t_{\max }\right)$ can be determined through parameters $B$ and $C$ as $\ln (1-C) / B$ (Richards 1959, Pienarr \& Turnbull 1973, Yen 2016).

As a result, parameter $A$ ranged from 49.97 to 80.94 , which increased with decreasing initial spacing, indicating that the growth potential $\left(\mathrm{BA} \mathrm{ha} \mathrm{ha}^{-1}\right)$ is negatively correlated with increasing initial spacing. However, parameters $B$ and $C$ appear without a clear 
trend with the initial spacing increasing or decreasing (Table 5). We further calculated the $t_{\max }$ from these two parameters based on the formula $\ln (1-C) / B$ and found values estimated to be $8.51,9.28,11.12$, and 15.49 years for treatments II, III, IV, and V, respectively. These results indicate that the $t_{\max }$ increases with increasing initial spacing. The parameters help explain some of the growth features of stands in relation to the effects of initial spacing.

\section{Conclusions}

The present study addressed the long-term effects of initial spacing on stand development for Japanese cedar. We used various growth functions to predict stand development at the plot level and found that the Richards growth function stood out among all the models after examination with RM-ANOVA. Subsequently, the Richards growth function was adopted to explore the relationship between stand growth and initial spacing at the treatment level. We found that this model was wellsuited to interpreting growth patterns of stand development resulting from different initial spacing. Moreover, the growth potential and $t_{\max }$ of stands can be easily explained by the parameters of the Richards function. The former decreases but the later increases with increases in initial spacing. Due to the lack of long-term survey data over a broad area for the Japanese cedar in Taiwan, we could not find enough information to determine the biological constraints for this conifer. Therefore, the present study only provides the trends of automatic forecasting produced by the Richards growth model without any assumptions.

This is also a limitation of the current study. Nevertheless, the results of this study could be regarded as the growth patterns quantified by the model resulting from different initial spacing. In fact, a broad area of Japanese cedar was planted in the mountainous areas of Taiwan, and numerous studies have addressed the growth and yield of this conifer due to its high economic and environmental benefits. Typically, the rotation age of Japanese cedar is below 40 years. Rarely do studies address the long-term effects of initial spacing for this conifer in Taiwan, especially over the course of 60 years. Our study provides longterm stand development information for the Japanese cedar extending over 20 years past the usual rotation age. These results should help improve the understanding of long-term stand development under different initial spacing for this conifer.

\section{References}

Baldwin V. C. Jr., Peterson K. D., Clark A. III, Ferguson R. B., Strub M. R., Bower D. R., 2000. The effects of spacing and thinning on stand and tree characteristics of 38-year-old loblolly pine. Forest Ecology and Management 137: 91-102. https://doi.org/10.1016/ S0378-1127(99)00340-0

Cheng C. H., Hung C. Y., Chen C. Peng., Pei C. W., 2013. Biomass carbon accumulation in aging Japanese cedar plantations in Xitou, central Taiwan. Botanical Studies 54:60. https://doi.org/10.1186/1999-3110-54-60.

Chiu C. M., Nigh G., Chien C. T., Ying C. C., 2010. Growth patterns of plantation-grown Taiwania cryptomerioides following thinning. Australian Forestry 73: 246-253. https://doi.org/10.1080/00049158.2010.10676335

Clutter J. L., Fortson J. C., Pienaar L.V., Brister G. H., Bailey R. L., 1983. Timber management: A quantitative approach. John Wiley \& Sons, Inc. 333 p.

Draper N. R., Smith H., 1981. Applied Regression Analysis. Second Edition. New York: Wiley.

Fukuda M., Iehara T., Matsumoto M., 2003. Carbon stock estimates for sugi and hinoki forests in Japan. Forest Ecology and Management 184(1-3):1-16. https://doi. org/10.1016/S0378-1127(03)00146-4

Gizachew B., Brunner A., Øyen B., 2012. Stand responses to initial spacing in Norway spruce plantations in Norway. Scandinavian Journal of Forest Research 27(7): 637-648. https://doi.org/10.1080/02827581.201 2.693191

Ito S., Osumi S., 1984. An analysis of the basal area growth in even aged pure stands based on the Richards growth function. Journal of Japanese Forest Society 66: 99-108.

Kitagawa R., Ueno M., Masaki T., 2018. Initial effects of thinning and concomitant disturbance on the understory woody community in Japanese cedar plantation. Journal of Forest Research 23(2):120-128. https://doi.org/10.10 80/13416979.2018.1430653 
Lam T. Y., Guan B. T., 2020. Modeling stand basal area growth of Cryptomeria japonica D. Don under different planting densities in Taiwan. Journal of Forest Research 25(3): 174-182. https://doi.org/10.1080/13416979.202 0.1733171

Lin C. J., Lin F. C., 2003. Ring characteristics of 95-year old Japanese cedar plantation trees grown in Taiwan. Scientific Research and Essays 8(8): 315-324.https:// doi.org/10.5897/SRE12.132

Liu Y. C., Lu F. Y., Ou C. H., 1994. Trees of Taiwan. Monographic Publication No. 7. College of Agriculture, National Chung-Hsing University, Taichung, Taiwan. R.O.C, pp. 63-64 (in Chinese).

Masaki T., Mori S, Kajimoto T., Hitsuma G., Sawata S., Mori M., Osumi K., Sakurai S., Seki T., 2006. Longterm growth analyses of Japanese cedar trees in a plantation: neighborhood competition and persistence of initial growth deviations. Journal of Forest Research 11(4): 217-225. https://doi.org/10.1007/s10310-0050175-6

Nishizono T., Tanaka K., Hosoda K., Awaya Y., Oishi Y., 2008. Effects of thinning and site productivity on culmination of stand growth: results from longterm monitoring experiments in Japanese cedar (Cryptomeria japonica D. Don) forests in Northeastern Japan. Journal of Forest Research 13(5): 264-274. https://doi.org/10.1007/s10310-008-0082-8

Richards F.J., 1959. A flexible growth function for empirical use. Journal of Experimental Botany, 10: 290300. https://doi.org/10.1093/jxb/10.2.290

Pienaar L. V., Turnbull K. J., 1973. The Chapman-Richards generalization of Von Bertalanffy's growth model for basal area growth and yield in even-aged stands. Forest Science. 19(1):2-22. https://doi.org/10.1093/ forestscience/19.1.2
Shih C. F., Liu K. F., Chen F. S., 1997. Spacing study in Cryptomeria plantation - 46 years old result. Journal of the Experimental Forest of National Taiwan University 11 (2): 81-109. (in Chinese with English summary).

TFB, 2020. Available at http://www.forest.gov.tw. Taipei, Taiwan: Taiwan Forestry Bureau (TFB). Accessed January 2020.

The Experimental Forest, College of Bio-Resources and Agriculture, National Taiwan University 2018. http:// www.exfo.ntu.edu.tw. Accessed January 2018.

Wang D. H., Chung C. H., Hsieh H. C., Tang S. C., Chen T. H., 2012. Site index model for Sugi plantation in Zenlen area, Taiwan. Taiwan Journal of Forest Science 27: 299-307.

Yen T. M., 2015. Relationships of Chamaecyparis formosensis crown shape and parameters with thinning intensity and age. Annals of Forest Research 58(2): 323-332. https://doi.org/10.15287/afr.2015.408

Yen T. M., 2016. Culm height development, biomass accumulation and carbon storage in an initial growth stage for a fast-growing moso bamboo (Phyllostachys pubescens). Botanical Study 57, 10. https://doi. org/10.1186/s40529-016-0126-x

Yen T. M., Huang K. L., Li L. E., Wang C. H., 2020. Assessing carbon sequestration in plantation forests of important conifers based on the system of permanent sample plots across Taiwan. Journal of Sustainable Forestry 39(4): 392-406. https://doi.org/10.1080/1054 9811.2019.1673181

Young Y. C., 1975. Study in the growth and harvest of Japanese cedar in National Taiwan University Experimental Forest. National Taiwan University Experimental Forest Research Report. No. 116 (in Chinese). 